\title{
Postpartum Dönemdeki Kadınların Doğuma Yönelik Duyguları ve Baş Etme Biçimleri: Nitel Bir Çalışma*
}

\author{
Pınar IRMAK VURAL*, Gülşah KÖRPE**
}

\section{$\ddot{\text { Öz }}$}

Amaç: Bu çalışmada postpartum dönemdeki kadınların gebelik süresince doğuma yönelik hissettikleri duyguların ve bunlarla baş etme biçimlerinin belirlenmesi amaçlanmıştır.

Yöntem: Bu çalışma postpartum dönemdeki 40 kadın ile gerçekleştirilmiştir. Araştırmada kullanılan veriler Nisan-Mayıs 2018 tarihlerinde görüşme yapılarak toplanmıştır. Veri toplama aracı kadınlara ait tanıtıcı bilgilerin olduğu bir "Tanıtıcı Özellikler Formu” ve yarı yapılandırılmış "Görüşme Formu” olarak iki bölümden oluşmaktadır.

Bulgular: Kadınların \%32,5’i 26-30 yaş aralığında olup, \%35’i üniversite mezunudur. Kadınlar en çok $(\% 44,08)$ korku duygusuna sahip oldukların ifade etmişlerdir. Kadınların \%27,78'si cerrahi girişimden korkmakta olup, doğum korkusu ile baş etmede dua etmeyi $(\% 41,81)$ kullandıkları bulunmuştur. Görüşme yapılan 40 kadının 37'si $(\% 92,5)$ annelik duygularının bütün olumsuz duyguları bitirdiğini ifade etmiştir.

Sonuç: Sonuç olarak çalışmaya katılan kadınların doğuma yönelik bilgi düzeylerinin oldukça düşük olmasının beraberinde olumsuz duyguları getirdiği belirlenmiştir. Aynı zamanda kadınların olumsuz duygularıyla geleneksel tipte baş etme davranışları gösterdikleri saptanmıştır.

Anahtar Sözcükler: Postpartum dönem, doğumsal, korku, başa çlkma, duygu.

\section{Emotions and Coping Strategies Related to the Birth of Women in the Postpartum Period: A Qualitative Study}

\section{Abstract}

Aim: In this study, it was aimed to determine the emotions and coping strategies related to the birth of women in the postpartum period.

Method: This study was carried out with 40 postpartum women. The data used in the research were collected through interviews in April-May 2018. The data collection tool consists of two parts, a "Descriptive Characteristics Form" with introductory information about women, and a semi-structured "Interview Form".

Results: $32.5 \%$ of the women were in the $26-30$ age range and $35 \%$ were university graduates. Women stated that they had the most fear (44.08\%). 27.78\% of women were afraid of surgical intervention and found

Özgün Araştırma Makalesi (Original Research Article)

Geliş / Received: 12.08.2021 \& Kabul / Accepted: 08.12.2021

DOI: https://doi.org/10.38079/igusabder.981956

${ }^{*}$ Bu çalışma, İstanbul Üniversitesi, 8. Kadın Doğum Günleri’nde sözel bildiri olarak sunulmuștur (6-9 Aralık 2018, Radisson Blu Şişli Hotel İstanbul).

${ }^{*}$ Dr. Öğr. Üyesi, İstanbul Medipol Üniversitesi, Sağlık Bilimleri Fakültesi, Hemşirelik Bölümü, İstanbul, Türkiye,

E-posta: pinar.irmak@windowslive.com ORCID https://orcid.org/0000-0002-8070-2840

${ }_{* *}$ Arş. Gör., İstanbul Medipol Üniversitesi, Sağlık Bilimleri Fakültesi, Hemşirelik Bölümü, İstanbul, Türkiye,

E-posta: gkorpe@medipol.edu.tr ORCID https://orcid.org/o000-0002-5192-7987

ETIK BILLIRIM: Araştırmanın uygulanabilmesi için İstanbul Medipol Üniversitesi Girişimsel Olmayan Klinik Araştırmalar Etik Kurulu Başkanlğ̆’ndan etik kurul onayı (433-25/o7/2018) ve kurum izni alınmışttr. Bu araştırma Helsinki Deklarasyonunda belirtilen ilkelere uyularak yürütülmüştür. 
that they used prayer to cope with the fear of birth (41.81\%). 92.5\% of women reported that maternal feelings ended all negative feelings.

Conclusion: It was determined that the knowledge levels of the women were very low and brought negative feelings. At the same time, it was found that women showed coping strategies of the traditional type with negative feelings.

Keywords: Postpartum period, congenital, fear, handling, feeling.

\section{Giriş}

Gebelik fiziksel ve psikolojik değişimlerin olduğu fizyolojik bir süreçtir ${ }^{1}$. Gebeler her trimester farklı fizyolojik ve emosyonel problemlerle baş etmek durumunda kalır. Gebeliğin ilk trimesterinde gebeliğe ilişkin yaşanan ambivalan duyguların yerini ikinci trimesterden itibaren ve özellikle gebeliğin üçüncü trimestrinde gebeliğe özgü anksiyete ve korku almaya başlar, duygulanımdaki şiddet ve anksiyeteye karşı olan savunma potansiyel olarak $\operatorname{artar}^{2}$. Kabul edilebilir düzeydeki korku kadının doğuma hazırlanmasında yardımcı olabilmektedir. Fakat doğum korkusu şiddetli düzeyde ise, doğum eyleminin gidişi olumsuz etkilenmekte, maternal ve neonatal komplikasyonların gelişmesine zemin hazırlayabilmektedir3.

Anksiyete ve korku; kortizol hormon seviyesinin artırmasına yol açarak obstetrik komplikasyonların gelişmesine neden olur. Doğumdan korkan kadınlar gebelikleri boyunca gece kabusları görmekte, fiziksel yakınmalar (sık idrara çıkma, mide yanması, bel-kasık ağrısı, mide bulantısı, nefes darlığı vb.) yaşamakta, işe veya ailesel aktivitelere konsantre olmada zorluklar yaşamakta ve sezaryen talebinde bulunabilmektedir. Ayrıca literatürde gebelik boyunca doğum korkusu devam eden gebelerde travay ve doğum sürecinde daha yoğun ağrı algısı yaşadığı, daha fazla epidural anestezi uygulandığı, ağrı intoleransı geliştiği, uzamış travay (özellikle doğumun ikinci evresi) ve sezaryen doğuma yatkınlığın arttığı bildirilmiştir²,3-6.

Doğum korkusu biyolojik, psikolojik ve sosyal faktörlerden etkilenebilmektedir. Düşük ağrı eşiğine sahip olma, doğum korkusunun en önemli biyolojik nedenlerindendir. Pariteye bakılmaksızın, doğum ağrısından korkma genel olarak ağrı korkusuyla bağlantılıdır ve isteğe bağlı sezaryenin en büyük sebebidir5. Nullipar kadınlar genellikle bilinmeyenden, doğum ağrısından ve kontrol kaybı yaşamaktan korkmaktadır. Multipar kadınların doğum korkusunun altında yatan temel neden ise ikincil doğum korkusu diye tanımlanan önceki doğum deneyimidir ${ }^{7,8}$. Gebenin bazı kişilik özellikleri (genel anksiyete, düşük benlik saygısı vb.) ve sosyo-ekonomik faktörler de doğum korkusu düzeyi ile doğrudan ilişkilidir 5 . Ayrıca gebeler doğum yapamama korkusuyla birlikte, kontrolünü kaybetme korkusu, umutsuzluk ve çaresizlik gibi çeşitli duygular hissederler9. Gebeler bu değişimlerle ilk ve ikinci trimesterde sıklıkla spiritüel ve emosyonel başa çıkma, ikinci ve üçüncü trimesterde hem emosyonel hem de problem odaklı başa çlkma tarzları kullanmaktadır ${ }^{10}$.

Bu araştırmanın amacı, postpartum dönemdeki kadınların gebelik süresince doğuma yönelik hissettikleri duyguların ve bunlarla baş etme biçimlerinin belirlenmesidir. $\mathrm{Bu}$ amaç doğrultusunda aşağıdaki sorulara yanıt aranmıştır:

- Gebelik süresince doğuma yönelik hissedilen duygular nelerdir?

- Gebelerin doğuma ilişkin korkuları varsa bu korkuların sebepleri nelerdir?

- Gebelik süresince olumsuz duygularla başa etme biçimleri nelerdir?

- Annelik duygusu gebelikte yaşanan olumsuz duyguları nasıl etkiler? 


\section{Gereç ve Yöntem}

\section{Araştırmanın tipi}

Bu çalışma, tanımlayıcı niteliksel araştırma desenine uygun olarak yapılmıştır. Nitel araştırmanın yapısı gereği, bu araştırmanın sonuçları topluma genellenememek ile birlikte, kadınların duygularına ve baş etme biçimlerine ilişkin derinlemesine veriler sunmaktadır.

\section{Araştırmanın Evreni ve Örneklemi}

Bu çalışma Nisan-Mayıs 2018 yılında İstanbul'da özel bir hastanede yürütülmüştür. Araştırmanın evrenini 15-49 yaşları arasında doğum yapan 370 kadın oluşturmaktadır. Veriler yeterli doygunluğa ulaştığında veri toplama işlemi sonlandırılmıştır. Çalışmaya katılmayı kabul eden ve çalışma kriterlerine uygun postpartum 1. günündeki 40 kadın ile gerçekleştirilmiştir. Çalışmaya kabul edilme kriterleri; okuma-yazmasının olması, riskli gebelik olmaması ve miyadında doğum yapmış olmasıdır. Çalışmada kadınların gerçek isimleri kullanılmamıştır. Bunun yerine kodlamada; kadın için "K”, sezaryen doğumu belirtmek için "CS”, normal vajinal yolla doğumu belirtmek için "NVD”, bireyin görüşme kodunu belirtmek için sıra sayı numaraları kullanılmıştır.

\section{Araştırmanın Veri Toplama Araçları}

Araştırmanın veri toplama aracı kadınlara ait tanıtıcı bilgilerin olduğu bir "Tanıtıcı Özellikler Formu” ve yarı yapılandırılmış "Görüşme Formu” olarak iki bölümden oluşmaktadır.

Tanıtıcı Özellikler Formu 15 sorudan oluşmakta olup, araştırmacılar tarafından oluşturulmuştur. Görüşme formu soruları belirlenmeden önce de araştırma konusuna ilişkin literatür taraması yapılmıştır. Araştırmanın amacına yönelik kadınlara sorulacak sorular belirlenmiştir. Araştırmada kadınlara yönlendirilen sorular şunlardır: Gebeliğiniz süresince doğumunuza yönelik hissettiğiniz duygularınız nelerdir? Doğuma ilişkin korkularınız var mıydı? Varsa; doğuma ilişkin korkularınızın sebepleri nelerdi? Olumsuz duygular hissettiğiniz zamanlarda bununla başa edebilmek için neler yaptınız? Şu anda annelik duygunuzun, gebelik ve doğum sürecinde hissettiğiniz olumsuz duygularınıza etkisi nedir? Belirlenen soruların amaç, anlam ve kapsam açısından değerlendirilmesi amacıyla 2 öğretim üyesi ve iki kadın ile görüşme yapılmıştır. Tüm bu aşamalardan sonra formun son hali oluşturularak, katılımcılarla görüşmelere başlanmıştır. Görüşmeler sadece araştırmacı ve kadının bulunduğu bir odada gerçekleştirilmiştir. Görüşmeler 20-25 dakika sürmüş ve görüşmelerde ses kayıt cihazı kullanılmıştır.

\section{Verilerin Analizi}

Kadınların tanımlayıcı verilerinin çözümlenmesinde yüzdelik dilimler ve frekans değerleri kullanılmıştır.

Görüşmelerle toplanan verilerin çözümlenmesinde içerik analizi yöntemi kullanılmıştır. Kadınların görüşme sorularına vermiş olduğu yanıtlar yazıya dökülmüştür. İçerik çözümlemesinde, ilk önce veriler kodlanmış, verilere ilişkin kategoriler (temalar) belirlenmiş, kodlar ve kategoriler organize edilerek bulgular tanımlanmış ve son olarak elde edilen bulgular yorumlanmıştır. Veriler kategorileştirilerek, verilerin hangi sıklıkla tekrar ettiği (frekans) hesaplanmıştır. Nitel veriler nicel verilere dönüştürülmüştür.

Nitel verilerin nicel verilere dönüştürülmesinde esas amaçlar; yanlılığı azaltmak, kategoriler arasında karşılaştırmalar yapmak ve güvenirliği arttırmaktır. ${ }^{11}$ Verilerin analizinde, toplamda ne kadar görüş ifade edildiğinin görülmesi açısından toplam frekanslar verilmiştir. Bazı sorularda kadınlar birden fazla görüş ifade etmişlerdir. Verilerin yorumlanmasında, kadınlara ait görüşler doğrudan aktarılmıştır. 


\section{Araştırmanın Etik Yönü}

Araştırmanın uygulanabilmesi için İstanbul Medipol Üniversitesi Girişimsel Olmayan Klinik Araştırmalar Etik Kurulu Başkanlığı'ndan etik kurul onayı (433-25/07/2018) ve kurum izni alınmıştır. Bu araştırma Helsinki Deklarasyonunda belirtilen ilkelere uyularak yürütülmüştür. Çalışmaya başlamadan önce kadınlara araştırmanın amacı, görüşme sırasında kayıt sisteminin kullanılacağı, elde edilen verilerin nerede ve niçin kullanılacağı açıklanarak kadınlar yazılı ve sözlü olarak bilgilendirilmiş ve gönüllü onamları alınmıştır.

\section{Bulgular}

Çalışmaya katılan kadınların \%85’i 20-35 yaş aralığında olup, \%37,5’inin eğitim düzeyi üniversite ve üzeridir. Kadınların \%65’i çalışmamakta, \%35’i primipar, \%75’i hiç düşük yapmamış ve \%17,5’i 1 veya 2 kez küretaj geçirmiştir. Kadınların \%60’ının daha önce emzirme deneyimi olmuştur. Kadınların \%67,5’inin gebeliği planlı, tamamının da kendiliğinden oluşmuştur. \%95’i doğuma hazırlık eğitimi almamıştır ve yalnızca bir kadın gebeliğe adaptasyon ile ilgili bir psikolojik desteğe ihtiyaç duymuştur. Kadınların \%34'ünde gebelik boyunca herhangi bir sağlık sorunu bulunmamaktadır. Kadınların \%80’inin 39-41. gestasyonel haftada doğum yaptığı belirlenmiştir. Doğan bebeklerin \%55’inin cinsiyeti erkek bebektir (Tablo 1).

Tablo 1. Kadınların tanıtıcı özellikleri $(n=40)$

\begin{tabular}{|c|c|c|}
\hline Tanıtıcı Özellikler & $\mathbf{n}$ & $\%$ \\
\hline \multicolumn{3}{|l|}{ Yaş } \\
\hline 20-35 yaş & 34 & 85 \\
\hline 36 yaş ve üzeri & 6 & 15 \\
\hline \multicolumn{3}{|l|}{ Ĕgitim durumu } \\
\hline İlkokul & 12 & 30 \\
\hline Ortaokul/Lise & 13 & 32,5 \\
\hline Üniversite ve üzeri & 15 & 37,5 \\
\hline \multicolumn{3}{|l|}{ Çalışma durumu } \\
\hline Evet & 14 & 35 \\
\hline Hayır & 26 & 65 \\
\hline \multicolumn{3}{|l|}{ Gebelik sayısı } \\
\hline 1 & 14 & 35 \\
\hline 2 & 10 & 25 \\
\hline 3 & 10 & 25 \\
\hline 4 ve üstü & 6 & 15 \\
\hline \multicolumn{3}{|l|}{ Düşük sayısı } \\
\hline Yok & 30 & 75 \\
\hline 1 & 7 & 17,5 \\
\hline 2 & 3 & 7,50 \\
\hline \multicolumn{3}{|l|}{ Küretaj sayısı } \\
\hline Yok & 33 & 82,5 \\
\hline 1 & 5 & 12,5 \\
\hline 2 & 2 & 5 \\
\hline \multicolumn{3}{|l|}{ Planlı gebelik } \\
\hline Evet & 27 & 67,5 \\
\hline Hayır & 13 & 32,5 \\
\hline \multicolumn{3}{|l|}{ Gebeliğin oluş şekli } \\
\hline Kendiliğinden & 40 & 100 \\
\hline Tedavi ile & $\mathrm{O}$ & $\mathrm{O}$ \\
\hline
\end{tabular}




\begin{tabular}{|c|c|c|}
\hline Gebelikte sağlık sorunu & & \\
\hline Hayır & 34 & 85 \\
\hline Gestasyonel diyabet & 3 & 7,5 \\
\hline Hipoglisemi & 1 & 2,5 \\
\hline Hipertansiyon & 2 & 5 \\
\hline \multicolumn{3}{|c|}{ Gebelikte psikolojik problem yaşama durumu } \\
\hline Hayır & 39 & 97,5 \\
\hline Adaptasyon sorunu & 1 & 2,5 \\
\hline \multicolumn{3}{|c|}{ Doğuma hazırlık eğitimi alma } \\
\hline Evet & 2 & 5 \\
\hline Hayır & 38 & 95 \\
\hline \multicolumn{3}{|c|}{ Doğum yapılan gebelik haftası } \\
\hline $36-38$ & 8 & 20 \\
\hline $39-41$ & 32 & 80 \\
\hline \multicolumn{3}{|l|}{ Emzirme deneyimi } \\
\hline Var & 24 & 60 \\
\hline Yok & 16 & 40 \\
\hline \multicolumn{3}{|l|}{ Doğum Şekli } \\
\hline Sezaryen & 19 & 47,5 \\
\hline Normal doğum & 21 & 52,5 \\
\hline \multicolumn{3}{|l|}{ Bebeğin cinsiyeti } \\
\hline $\mathrm{K} ı$ & 18 & 45 \\
\hline Erkek & 22 & 55 \\
\hline
\end{tabular}

Yapılan görüşmeler sonrasında elde edilen verilerin sonucunda 4 adet ana temaya ulaşılmıştır.

Tema 1. Doğuma ilişkin duygular

Çalışmaya katılan kadınların doğuma ilişkin en çok oranda $(\% 44,08)$ korku duygusuna sahip olduklarını ifade etmişlerdir (Tablo 2).

“Gebelik boyunca en çok doğumdan korktum, en çok bunu düşündüm.” K.NVD.31

"Gebelikten değil de doğumdan korkuyordum. Sonuç olarak bıçak altına yatıyorsun. Bu insanı tedirgin ediyor. Hatta bu yüzden ikinci doğumumu normal doğum yapmak istedim ama olmadı.” K.CS.14

Tablo 2. Kadınların doğuma ilişkin duyguları

\begin{tabular}{|l|l|l|}
\hline Duygular* & $\mathbf{N}$ & $\mathbf{\%}$ \\
\hline Korkmuş & $\mathbf{2 6}$ & 44,08 \\
\hline Heyecanlı & $\mathbf{1 4}$ & $\mathbf{2 3 , 7 2}$ \\
\hline Tedirgin & $\mathbf{8}$ & $\mathbf{1 3 , 5 6}$ \\
\hline Mutlu & 7 & $\mathbf{1 1 , 8 6}$ \\
\hline Mutsuz & $\mathbf{2}$ & 3,39 \\
\hline Sıkıntılı & $\mathbf{2}$ & 3,39 \\
\hline Toplam & 59 & $\mathbf{1 0 0}$ \\
\hline
\end{tabular}

*Birden çok yanıt verildiğinden yüzdeler katlanmış n üzerinden verilmiştir. 
Tema 2. Doğum korkusunun sebepleri

Kadınlara yöneltilen “Doğuma ilişkin korkularınız var mıydı?” sorusunu 37'si evet olarak yanıtlamıştır. Doğum korkusu olduğunu ifade eden kadınlarla doğum korkusunun sebeplerine yönelik yapılan derinlemesine görüşmede kadınların \%27,78'si cerrahi girişimlerden, \%18,51’i sosyal çevrelerinin etkisinden, \%14,81'i doğum ağrısından, \%12,97'si önceki deneyimlerden, \%12,97'si bilgi eksikliğinden, \%9.26'sı doğum sancısından ve \%3,7'si ise bebeğin güveliğinin sağlanmasına ilişkin kaygılardan dolayı doğumdan korktuklarını ifade etmişlerdir (Tablo 3).

“Üç yıl sonra tekrardan sancı çekmekten, doğum yapmaktan korktum.” K.NVD.40

“Ameliyattan korkuyordum. Anesteziyle uyuyup uyanamamaktan korktum.” K.CS.16

"Etrafimdaki herkes normal doğumun zor olduğunu söylüyordu. Gereksiz yere çok dikiş atıldığını ve her şeyi hissettiğini söylüyorlardı.” K.NVD.34

“Bilinmezlik korkusu, çünkü ne yapacağımı bilmiyordum.” K.NVD.31

“A ğrıı hissetmekten korktum.” K.CS.22

“İlkinde suni sancı olduğu için bunda da suni sancı olacak sandım ve korktum.” K.NVD.27

“Bebeğime bir şey olacak, kucağıma alamayacağım diye korktum.” K.CS.10

Tablo 3. Doğum korkusunun sebepleri

\begin{tabular}{|l|l|l|}
\hline Korku sebepleri $^{*}$ & N & \% \\
\hline Cerrahi girişim & 15 & $\mathbf{2 7 , 7 8}$ \\
\hline Sosyal çevrenin etkisi & 10 & 18,51 \\
\hline Doğum ağrısı & 8 & 14,81 \\
\hline Bilgi eksikliği & 7 & 12,97 \\
\hline Önceki deneyimler & 7 & 12,97 \\
\hline Doğum sancıları & 5 & 9,26 \\
\hline Bebeğin güvenliği & $\mathbf{2}$ & 3,70 \\
\hline Toplam & 54 & 100 \\
\hline
\end{tabular}

*Birden çok yanıt verildiğinden yüzdeler katlanmış $n$ üzerinden verilmiştir.

Tema 3. Kadınların olumsuz duyguları ile baş etme yöntemleri

Baş etme biçimlerine yönelik görüşme verilerine göre; kadınların \%41,81'i dua ederek, \%16,36'sı aklına getirmeyerek, \%14,54'ü olumlama yaparak, \%12,73’ü sosyal destek alarak, \%3,64’ü nefes egzersizi yaparak ve \%1,81’i kitap okuyarak baş ettiklerini ifade etmişlerdir. Kadınların \%9,10’u olumsuz duygularla baş etmek için hiçbir şey yapmadıklarını belirtmişlerdir (Tablo 4).

“Bol bol dua ettim, başka şeylerle uğraştım.” K.NVD.39

“Dua okuyarak üstesinden geldim.” K.CS.2

“Korkularımı eşimle paylaştım.” K.CS.8

“Ailemin desteğini aldım.” K.NVD.32

"Doğum aklıma geldiğinde düşünmemeye çalsştım. Etrafimda konuşulanları duymamak için ortamdan uzaklaştım.” K.NVD.33

“Bebeğimle geçireceğim zamanları düşünerek kendimi rahatlatmaya çalıştım.” K.NVD.22 
Tablo 4. Kadınların olumsuz duygular ile baş etme yöntemleri

\begin{tabular}{|l|l|l|}
\hline Baş etme yöntemi $^{*}$ & N & \% \\
\hline Dua etmek & 23 & 41,81 \\
\hline Aklına getirmemek & 9 & 16,36 \\
\hline Olumlama yapmak & 8 & 14,54 \\
\hline Sosyal destek & 7 & 12,73 \\
\hline Hiçbir şey yapmamak & 5 & 9,10 \\
\hline Nefes egzersizi & 2 & 3,64 \\
\hline Kitap okumak & 1 & 1,82 \\
\hline Toplam & 55 & 100 \\
\hline
\end{tabular}

*Birden çok yanıt verildiğinden yüzdeler katlanmış $n$ üzerinden verilmiştir.

Tema 4. Annelik duygusunun olumsuz duygulara etkisi

Görüşme yapılan 40 kadının 37'si (\%92,5) annelik duygularının bütün olumsuz duyguları bitirdiğini belirtirken, kadınlardan 1'i postnatal ağrı sebebiyle, 1’i hormonların artması sebebiyle kaygı ve korkularının devam ettiğini, 1’i ise plansız gebelik sebebiyle diğer çocuklarına karşı suçluluk hissetmesi sebebiyle olumsuz duygulanımda olduğunu ifade etmiştir.

“Anne olunca bütün korkularm geçti”. K.CS.5

“Annelik duygum tüm korkularımı ve acılarımı bastırdı. K.CS.7

“Anne olmak bütün korkuları yok ediyor. Bebeğim için her şeye değer.” K.NVD.21

"Doğduğu an bütün korkulartmı, olumsuz hislerimi geride biraktım. Şu an çok mutluyum". K.NVD.31

\section{Tartışma}

Çalışmaya katılan kadınlara doğuma yönelik duyguları sorulduğunda en çok korku $(\% 44,08)$ hissettiklerini ifade etmiştir. Çalışmalarda doğum korkusu prevalansı kültürel özellikler, gebelik haftası ve doğum korkusunu tespit etme yöntemindeki farklılıklar nedeni ile değişik oranlarda rapor edilse de ortalama \%15-20 olarak bildirilmektedir ${ }^{12,13}$. Bu çalışmanın sonuçlarına göre kadınların \%88,14'ünün doğuma ilişkin olumsuz duygulara sahip olduğu belirlendi (Tablo 2). Çalışmaya katılan kadınların sadece \%5’inin gebelik döneminde doğuma hazırlık eğitimi almış olması bilgi düzeylerinin oldukça düşük olduğunu ortaya çıarmaktadır. Bilgi düzeyinin düşük olmasıyla beraber olumsuz deneyimlerin özellikle korkuya sebep olduğu düşünülmektedir.

Doğumdan korktuğunu ifade eden kadınlar en çok cerrahi süreçten korktuklarını ifade etmişlerdir. Çalışmaya katılan bir kadın "İlk doğumum sezaryen olduğu için kesilmekten, uyumaktan ya da uyanamamaktan korkuyorum." (K.CS.5), bir başkası da "Ameliyattan korkuyorum, anesteziyle uyuyup uyanamamaktan korkuyorum.” (K.CS.16) sözleriyle ifade etmişlerdir. Literatüre baktığımızda doğuma yönelik korkuları ortaya koyan birçok çalışma bulunmaktadır. Bu çalışmalarda kadınların; doğum ağrısı, ölüm, panik olma, yanlış bir davranışta bulunarak fetüse veya kendine zarar verme, acilen sezaryen doğuma alınma, kanama, plasenta parçasının içerde kalması, doğum sırasında komplikasyon gelişmesi, bebeğinin zarar görmesi, ölmesi, bebekte kalıcı bir hasar olması ve doğumda perinenin hasar görmesi, epizyotomi, sağlık personelinin yeterince destek olmamasından korktukları saptanmıştır ${ }^{14-18}$. Bu çalışmaları destekler şekilde bir kadının "Bebeği doğururken bebeğin zarar görebilmesi ihtimalinden dolayı sezaryeni seçtim." (K.CS.3), bir diğerinin de "Sancı çekmekten korkuyorum." (K.NVD.40) ifadeleri literatürü desteklemektedir. Doğuma hazırlık sınıflarına gelen gebelerde yapılmış bir çalışmada gebelerin \%50'sinin bebeğine zarar geleceğinden, \%40'ının ise ağrıdan korktuğu 
saptanmıştır ${ }^{19}$. Bülbül ve arkadaşlarının çalışmasında gebelerin \%28,6'sının doğum korkusu nedeniyle sezaryen ile doğumu tercih ettikleri belirlenmiştir ${ }^{20}$. Sezaryen doğumu tercih eden gebelerin ortalama \%35’inin doğum ağrısından korktuğu tespit edilmiştir ${ }^{21,22}$. Bu çalışmada da sezaryen doğum oranı \%47,5 olarak saptanmıştır. Bu durumda; gebeler doğum korkusuyla baş edebilirlerse sezaryen oranının azalabileceği düşünülmektedir.

Çalışmaya katılan kadınların \%41,81’i dua ederek olumsuz duygularla baş etmeye çalıştığını ifade etmişlerdir. Spiritüalite, günlük yaşamın metafizik ya da bilinç ötesi özelliklerini, kişinin dışında var olan doğaüstü ya da başka türlü güçlerle ilişkisi bağlamında açıklayan çabalar olarak tanımlanmaktadır²3. Bireylerin bütünlüğü ve daha yüksek bir varlığa bağlı olmaları varsayımıyla evrensel bir insan fenomeni olarak tanımlanır ve yaşamdaki anlam ve amaç arayışını bütünleştirir ${ }^{24}$. Gebelik, herhangi bir sağlık problemi olmasa bile stresli ve karmaşık bir süreçtir, dolayısıyla bütüncül bakım felsefesi doğum sürecinde önem kazanmaktadır. Bu süreç gebe ve ailesinin bir bütün olarak ele alınmasını, bu yeni duruma uyum sağlayabilmeleri için bakım ve eğitim gereksinimlerinin karşılanmasını, gebenin karşılaşabileceği stresörlerin farkında olunmasını, etkili baş etme yöntemlerinin kullanılmasının sağlanmasını gerektirir ${ }^{25}$. Çalışmaya katılan kadınların hepsi herhangi bir baş etme yöntemi belirlese de \%92,5’i annelik duygusunun bütün olumsuz duyguları bitirebileceğini ifade etmiş̧lerdir. Çalışmaya katılan bir kadın bu konuya yönelik duygularını "Anne olmak bütün korkuları yok ediyor, bebeğim için her şeye değer." (K.NVD.21) şeklinde ifade etmiştir. Bir çalışmada da doğumda ağrı deneyimi yaşamanın annelik duygularını güçlendirdiğini ve normal doğum yapmanın çekilen ağrılara/sancıya rağmen annelik duygusunu güçlendirdiğini ifade etmişlerdir. Çalışmaya katılan kadınlardan biri "Acı çekince anne olmayı daha iyi anlıyorum.” ifadesiyle acı çekmenin annelik duygusunu daha güçlendirdiği ve acıyı/ağrıyı olumlu yönde algılamasına olanak sağladığı belirlenmiştir²6.

Nitel araştırmaların güçlü yönlerinden biri, araştırmacıya birey tarafından yaşanmış bir deneyimi anlama ve anlamlandırma olanağı sunmasına rağmen araştırma sonuçlarının genellemeye uygun olmaması, uygun katılımcıların belirlenmesinin zorluğu ve araştırmacı önyargısını belirlemenin güçlüğü sınırlılıkların arasındadır. Bu bağlamda sadece İstanbul ilinin merkezinde özel bir hastanede yürütülmüss olması nedeniyle genellemenin yapılamaması bu çalışmanın sınırlılığıdır.

Araştırmanın uygulanabilmesi için İstanbul Medipol Üniversitesi Girişimsel Olmayan Klinik Araştırmalar Etik Kurulu Başkanlığı'ndan etik kurul onayı (433-25/07/2018) alınmıştır. Yazarlar arasında çıkar çatışması bulunmamaktadır.

\section{Sonuç}

Sonuç olarak çalışmaya katılan kadınların doğuma yönelik bilgi düzeylerinin oldukça düşük olmasının beraberinde olumsuz duyguları getirdiği belirlenmiştir. Kadınlar doğuma yönelik olumsuz duygusunun en çok "korku" olduğunu ifade etmişlerdir. Korkuya sebep olan en büyük faktörün de doğum sırasında yapılan veya yapılacak olan cerrahi girişimler olduğu belirlenmiştir. Kadınların olumsuz duygularıyla geleneksel tipte baş etme davranışları gösterdikleri, en çok dua ederek korkularıyla baş etmeye çalıştıkları saptanmıştır. Gebelerin doğum eylemi hakkında hem kognitif hem de psikolojik açıdan desteklenmesi, doğum şeklinin belirlenmesinde hem bireysel hem de toplumsal açıdan olumlu sonuçlara neden olacağı düşünülmektedir. Aynı zamanda araştırmanın sonucunda kadınların en çok spiritüel baş etme davranışı gösterdikleri göz önüne alınarak, perinatal hemşirelik bakım sürecinde spiritüel bakımın gebelerin iyi oluşunda yerinin oldukça önemli olduğu ortaya çıkarılmıştır. Postpartum dönemdeki kadınların duygularının ve olumsuz duygularla baş etme davranışlarının belirlenmesi ile ilgili kanıt temelli çalışmaların yapılması önerilmektedir. 


\section{KAYNAKLAR}

1. Brunton RJ, Dryer R, Saliba A, Kohlhoff J. Pregnancy anxiety: A systematic review of current scales. Journal of Affective Disorders. 2015;176:24-34.

2. Stoll K, Swift EM, Fairbrother N, Nethery E, Janssen P. A systematic review of nonpharmacological prenatal interventions for pregnancy-specific anxiety and fear of childbirth. Birth. 2018;45(1):7-18.

3. Alessandra S, Roberta L. Tokophobia: When fear of childbirth prevails. Mediterranean Journal of Clinical Psychology. 2013;1(1):1-18.

4. Uçar T, Gölbaşı Z. Nedenleri ve sonuçlarıyla doğum korkusu. İnönü Üniversitesi Sağhk Bilimleri Dergisi. 2015;4(2):54-8.

5. Saisto T, Halmesmaki E. Fear of childbirth: A neglected dilemma. Acta Obstetricia et Gynecologica Scandinavica. 2003;82(3):201-8.

6. Sydsjö G, Angerbjörn L, Palmquist S, Bladh M, Sydsjö A, Josefsson A. Secondary fear of childbirth prolongs the time to subsequent delivery. Acta Obstetricia et Gynecologica Scandinavica. 2013;92(2):210-14.

7. Rouhe H, Salmela-Aro K, Halmesmäki E, Saisto T. Fear of childbirth according to parity, gestational age, and obstetric history. An International Journal of Obstetrics \& Gynaecology. 2009;116(1):67-73.

8. Storksen HT, Garthus-Niegel S, Vangen S, Eberhard-Gran M. The impact of previous birth experiences on maternal fear of childbirth. Acta Obstetricia et Gynecologica Scandinavica. 2013;92(3):318-24.

9. Hamilton JG, Lobel M. Types, patterns, and predictors of coping with stress during pregnancy: Examination of the revised prenatal coping inventory in a diverse sample. Journal of Psychosomatic Obstetrics \& Gynecology. 2008;29:97-104.

10. Yıldırım A. Şimşek H. Sosyal Bilimlerde Nitel Araştırma Yöntemleri. 2. baskı. Ankara: Seçkin Yayıncılık; 2005.

11. Fenwick J, Gamble J, Nathan E, Bayes S, Hauck Y. Pre-and postpartum levels of childbirth fear and the relationship to birth outcomes in a cohort of Australian women. Journal of Clinical Nursing. 2009;18(5):667-77.

12. Hall WA, Hauck YL, Carty EM, Hutton EK, Fenwick J, Stoll K. Childbirth fear, anxiety, fatigue, and sleep deprivation in pregnant women. Journal of Obstetric, Gynecologic, \& Neonatal Nursing. 2009;38(5):567-76.

13. Ryding EL, Wijma B, Wijma K, Rydhström H. Fear of childbirth during pregnancy may increase the risk of emergency cesarean section. Acta Obstetricia et Gynecologica Scandinavica. 1998;77(5):542-7.

14. Saisto T, Ylıkorkala O, Halmesmaki E. Factors associated with fear of delivery in second pregnancies. Obstetrics \& Gynecology. 1999;94(5):679-82.

15. Melender HL. Experiences of fears associated with pregnancy and childbirth: a study of 329 pregnant women. Birth. 2002;29(2):101-11. 
16. Kwee A, Cohlen BJ, Kanhai HH, Bruinse HW, Visser GH. Caesarean section on request: a survey in The Netherlands. European Journal of Obstetrics \& Gynecology and Reproductive Biology. 2004;113(2):186-90.

17. Serçekuş $P$, Okumuş $H$. Fears associated with childbirth among nulliparous women in Turkey. Midwifery. 2009;25:155-62.

18. Geissbuehler V, Eberhard J. Fear of childbirth during pregnancy: a study of more than 8000 pregnant women. Journal of Psychosomatic Obstetrics \& Gynecology. 2002;23(4):229-35.

19. Bülbül T, Özen B, Çopur A, Kayacık F. Investigation the fear of labor and decision making about delivery type in pregnant. Journal of Health Sciences. 2016;25(3):126-30.

20. Gözükara AGF, Eroğlu K. İlk doğumunu yapmış kadınların (primipar) doğum şekline yönelik tercihlerini etkileyen faktörler. Hacettepe Üniversitesi Hemşirelik Fakültesi Dergisi. 2008;15(1):32-46.

21. Yağmur Y, Çubuk MM. Kadınların doğum şekli tercihlerine sağlık eğitiminin etkisi. İnönü Üniversitesi Sağlik Bilimleri Dergisi. 2017;6(1):7-11.

22. Jenkins RA, Pargament K. I. Religion and spirituality as resources for coping with cancer. Journal Psychosocial Oncology. 1995;13(1-2):51-74.

23. Sira N, Desai PP, Sullivan KJ, Hannon DW. Coping strategies in mothers of children with heart defects: A closer look into spirituality and internet utilization. Journal of Social Service Research. 2014;40(5):606-22.

24. Ölçer Z, Oskay Ü. Yüksek riskli gebelerin yaşadığı stresörler ve stresle baş etme yöntemleri. HEAD. 2015;12(2):85-92.

25. Duran E., Atan ŞÜ. Kadınların sezaryen/vajinal doğuma ilişkin bakış açılarının kalitatif analizi. Genel Trp Dergisi. 2011;21(3):83-88.

26. Duran E., Atan ŞÜ. Kadınların sezaryen/vajinal doğuma ilişkin bakış açılarının kalitatif analizi. Genel Trp Dergisi. 2011;21(3):83-88. 